\title{
Optimizing the Development of Emotional Competence in Early Childhood
}

\author{
Yettie Wandansari ${ }^{\mathrm{a}}$, Dewi Retno Suminar ${ }^{\mathrm{a}}$, Tina Afiatin ${ }^{\mathrm{b}}$ \\ ${ }^{\text {a }}$ Faculty of Psychology, Airlangga University, Surabaya, Indonesia \\ ${ }^{\mathrm{b}}$ Faculty of Psychology, Gadjah Mada University, Jogjakarta, Indonesia \\ Corresponding e-mail: yettie_w@yahoo.com
}

\begin{abstract}
The concept of emotional competence refers to individual differences in emotional expression and experience, understanding, and regulation. Previous studies reported the significant roles of emotional competence in children's development of social and school competence. One of the antecedent factors of emotional competence development in early childhood is parental socialization of emotion. The possible mechanisms of parental socialization of emotion can be classified in three categories, namely modeling, contingency, and coaching. Furthermore, emotion socialization by parents cannot be separated from the cultural context. Cultural values do not only affect the way individual recognizes his or her own emotion and the emotion of others, but also determine how individual expresses emotion and regulates emotion in socially acceptable ways. This paper is a literature review of some research findings of emotional socialization and theoretical approaches of cultural values roles on emotion competence. It aims to explore the roles of parental emotion socialization and culture values, which can be used as a basis to further research in creating culturebased interventions to optimize the development of early childhood emotional competence in Indonesia.
\end{abstract}

Keywords: early childhood, emotion socialization, culture, emotional competence.

\section{INTRODUCTION}

Children become increasingly emotionally competent through the life span. Broadly stated, aspects of emotional competence include emotional expression and experience, understanding emotions of self and others, and emotion regulation (Denham et al, 2003).

The importance of emotional competence can be known based on the results of previous studies showing that children's emotional competence is correlated with the two main things, namely social skill and school competency, which will be discussed below.

The ability to manage emotions positively correlated with the quality of social interaction, social adaptation, higher empathy, and fewer negative peer interactions (Lopez et al, 2004). Children who are able to express their emotions effectively both verbally and non-verbally tend to be adaptive to social norms when they communicate their feelings, so that they get support from teachers and friends and feel more comfortable at school (Brackett \& Katulak, 2006). Adaptive emotion regulation strategies by children at an early age predict poor peer rejection in middle childhood and low anti-social behavior in early teens (Trentacosta \& Shaw, 2009). Prosocial behavior of preschoolers correlated with high emotional understanding and empathy, while the hostile behavior correlated with the lack of emotion understanding (Farina \& Belacchi, 2014).
Conversely, low emotional skill correlated with abnormal behavior and poor relationships (Brackett et al, 2004). The inability to assess others' expression of emotions directly related to the violence and aggression of children, because aggressive children tend to be too sensitive in perceiving other people's negative emotions (Brackett \& Katulak, 2006). Lack of control over his behavior in class have a negative impact on a child's ability to pay attention and understand the material being taught by teachers and to accomplish the tasks at school (Graziano et al., 2007). Students with low emotional skills also showed higher impulsivity, lower social and interpersonal skills, thereby strengthening the rise of antisocial behavior and self-destructive behaviors such as smoking or consuming drugs in adolescence (Fernandez-Berrocal \& Ruiz, 2008).

Furthermore, emotional competence is also an important predictor for the individual ability to adapt to the environment. Kindergarten students' ability to regulate emotions positively associated with their academic success, the students' productivity in the classroom and good performance in reading and mathematics (Graziano et al., 2007). The child's ability to efficiently manage their emotions will help children in the transition process and will develop children's' academic ability (Graziano et al, 2007). Emotion regulation skill in children contributes to academic success, mediated by the control over the children's behavior in the classroom (Graziano et al., 2007). Preschoolers' knowledge about emotion 
correlates directly with school competence, whereas the relationship between teacher-child closeness and children's competence mediated by the children's knowledge about emotions (Garner \& Waajid, 2008). Emotional competence and social competence proved to be a predictor of school adjustment in children (Magdalena, 2013).

This paper is a literature review of some research findings of two antecedent factors of emotional competence development in early childhood, namely parental emotional socialization and cultural values. It aims to explore the roles of both factors which can be used as a basis to further research in creating culturebased interventions to optimize the development of early childhood emotional competence in Indonesia.

\section{LITERATURE REVIEW}

\subsection{Parental Emotion Socialization}

Parents play a major role in the development of emotional competence of children through emotion socialization. The socialization process takes place throughout children's development, even since the infant stage, through the ways parents communicate and calm down their infants, which further develop the infant's ability to recognize and to respond the facial emotional expression (Halberstadt \& Lozada, 2011). Various studies have also confirmed the role and impact of emotional socialization by parents on children's ability to recognize emotions, to express emotions, and to regulate emotion, which will be described as follows. Based on the literature reviews on a number of articles published in scientific psychological journals (Proquest, ScienceDirect, Sage Journals Online, Springer link, and Google Scholar), with the keyword "emotional competence", "emotion development", "emotion and early childhood", "emotion socialization"," culture and emotion socialization, these articles further were classified into 3 groups of emotion socialization possible mechanisms stated by Halberstadt (in Denham et al, 1997). The three possible mechanisms of emotion socialization are modeling, contingency, and coaching.

The first mechanism according to Halberstadt is modeling hypothesis, states that the ways parent's express emotions implicitly teach children about emotions that are expected and acceptable in the family, as well as how certain situations can bring out certain emotions. Through modeling, parents also indirectly teach children how to express and regulate emotions. Nelson, O'Brien, Calkins, Leerkes, and Marcovitch (2012) reported differences in the development of emotion regulation in terms of maternal child expressive style. Mothers who have high maternal expressive style (very expressive in positive emotions and less expressive in negative emotions) have children with better emotion regulation. Associated with the physiological regulation, parents who have high resting vagal tone (indicating the higher regulation ability) implement socialization of emotion through better expression of emotions, and have children with better knowledge of emotions (Perlman, Camras, \& Pelphery, 2008).

The second mechanism according to Halberstadt is contingency hypothesis, stating that the response of parental support will help children to maximize the expression of positive emotions, to minimize the expression of negative emotions, and to distinguish among emotions. Emotional support, such as accepting children's emotions or soothing the children when they are angry, basically teaches children to tolerate and to control emotions. Ashiabi (2000) reported that caregivers contribute to the development of children's emotions by reading the cues of child's emotion accurately and responding those cues sensitively; moreover, precise and consistent responsiveness of caregivers will help children to regulate emotions and eventually develop the emotional competence in children. In relation with maternal roles, maternal emotion socialization (includes emotional expression, emotional response to the child, and the emotional conversation between mother and child) can be predictor of children's emotion self-awareness for the next 1 year.

Supportive maternal emotional socialization is a predictor of high emotion self-awareness for positive emotion, whereas a non-supportive maternal emotion socialization of mothers is a predictor of low emotion self-awareness for negative emotions in children (Warren \& Sifter, 2007). Maternal support when responding to stress in children correlated with the child's understanding of emotion regulation strategies, and that understanding has implications for the child's behavior regulation (Cole, Dennis, Smith-Simon, \& Cohen, 2009). Conversely, mothers who neglect children less support the expression of children's emotions, less discussions about emotions, had more negative emotions, and their children demonstrated lower understanding of emotions than children who were raised well by their mother (Edwards, Shipman \& Brown, 2005).

Type of parental response to the child's emotional responses can also be classified into problem-focused responses and emotion-focused responses, where the problem-focused reaction of parents positively correlated with boys' socio-emotional competence in boy; while punishing, reaction correlated with lower socio-emotional competence of children (Jones, Eisenberg \& Fabes, 2002). Parental punishing 
reaction also positively predicted externalizing problems in children, while emotion-focused reactions and problem-focused reactions negatively correlated with internalizing problems in children (Tao, Zhou, \& Wang, 2010).

The third mechanism according to Halberstadt is coaching hypothesis, stating that the ways parents teaches emotions contribute to the child's emotional expression and emotional reaction to their peers. Those ways can be differentiated into two types. The first type is the parent as a "coach" who understand children's emotions, especially negative emotions, and help children to experience and regulate emotions. The second type is the parent as "dismisser" who want to help but ignore the child's emotional experience. Inviting children to participate in discussions about emotions basically provide a tool for children to manage their emotions, so that emotion regulation can be transferred from an external (parents soothe the child while crying) to internal (children calm down themselves). Lunkenheimer, Shields, and Cortina (2007) reported their research findings on parental emotion coaching (EC) and dismissing emotion (ED) in the family interaction that ED is a risk factor that contribute to poor emotional regulation and behavioral problems. EC does not directly contribute to the child's emotions and behavior, but interact with ED to protect children from the adverse effects of ED, particularly for negative emotions. In the emotional interaction in the family, EC and ED has a complex interaction as risk and protective dimension for the family.

In terms of the development of parenting skills to do emotion coaching, Havighurst, Harley, and Prior (2004) reported that "Parenting Program" proved to be effective for improving the emotion competence of children. Parents encouraged children's' emotional expression, applied emotion-focused approach in interacting with children, and reduced criticism to the children's emotion expression. Children also showed a decrease in negative emotions and problematic behavior. Furthermore, Havighurst, Wilson, Hary, Prior, and Kehoe (2010) reported the effectiveness of the program "Tuning in to Kids" to improve socialization of emotion by the parents of the preschoolers. The results showed the effectivity of the program, in which the parents had an increase in emotion regulation, emotional self-awareness, and emotion coaching, as well as a decline in terms of beliefs and their inappropriate behaviors.

\subsection{The Role of Cultural Values on Emotional Competence Development}

Parental emotion socialization is closely affected by cultural context. Culture values does not only affect the way individual identifies emotions, but also how individuals express and manages emotions in a way that is socially acceptable. Culture would restrict and regulate to whom, when and where any person may reveal and conceal certain emotions, as well as in the way of emotion expression through nonverbal behaviors and facial expressions (Ekman, 1992, in Kurniawan \& Hasanat, 2007). For example, in contrast to individualistic culture, collectivistic culture that promotes a harmonious social relationship tends to be less supportive of the open expression of negative emotions. It is associated with the view of collectivism that the expression of strong emotions showed inability to control themselves, so parents in the socialization of emotions are less likely to support children's strong emotional expressions.

Furthermore, Halberstadt and Lozada (2011) identified five "cultural frames" of Markus and Kitayama for socialization of emotion, namely collectivism or individualism, power distance, children's place in family and culture, ways children learn, and value of emotional experience and expression. Through those five "cultural frames", parental emotion socialization can be explained and be understood holistically.

The first cultural frame consists of collectivism and individualism. Culture of collectivism emphasizes interdependence, group identity, interpersonal harmony, and the achievement of shared goals. Emotions are characterized by self-control to promote interpersonal harmony and group goals. In contrast, the culture of individualism emphasizes independence, individual identity, personal assertion, and achievement of personal goals. Emotions are perceived to be unique to the individual, emotion expressiveness may be encouraged, and emotions are identified on the basis of intrapersonal, subjective experience. In the socialization of emotions, parents with collectivism cultural backgrounds tend to support their children to share with other children, while parents who are influenced by individualism culture tend to encourage their children to explore the environment individually (Halberstadt \& Lozada, 2011).

Wang (2006) also reported that in Euro-American culture that emphasizes individuality and autonomy, emotion is regarded as a direct expression of the uniqueness of the individual. Middle-class EuroAmerican parents tend to support their children to articulate their own emotions and feelings so that 
ultimately their need is fulfilled. In contrast, Asian parents tend to emphasize psychological and behavioral standards rather than to help their children express or understand emotions. In Indonesia, particularly, children would be expected early on to learn to conform to group norms in terms of controlling the overt expression of negative emotion and emotionally driven negative behavior, so that they behave in a manner that promotes group harmony and avoids interpersonal conflict (Eisenberg, Pidada, \& Liew, 2001).

The second cultural frame is power distance (Hofstede, 2001, in Halberstadt \& Lozada, 2011). Cultures with strong power distance recognize the inequalities in social relationship and emphasize the values of obedience, respect for authority, and adhere to the rules. In contrast, cultures with less power distance emphasize equality in social relationship, encourage democratic values, and allow for dialogue in the hierarchy of power. Power distance can also be reflected in the parental emotion socialization purposes. Strong power distance encourages parents to support children to be obedient and respectful to them and tends to use one-way communication, while less power distance is encouraging parents to dialogue with children and to provides opportunities for children to express their opinions. For example, Wang \& Fivush (2005) stated that when talking about the experience positive and negative emotions with children, Euro-American mothers initiated more interactive and elaborative conversations, gave support to facilitate the child's participation, and focused on the child's own emotions. In contrast, Chinese mothers took a directive role in memory repeating questions and frequently to social interaction and significant others. Furthermore, in regulating negative emotions, Euro-American mothers talked frequently about the causes of the child's feeling and provided elaborate explanations about the emotion. They were also accepting the child's negative emotions and reassure the child that everything was all right. Conversely, Chinese mothers initiated less discussion to help children understand their feeling and commented on the child's emotions in a way to "teach the child a lesson" that his or her negative emotional experience and rule-violating behaviors are unacceptable.

The third frame is children's place in family and culture (Halberstadt \& Lozada, 2011). There are variations of children's values in different cultures. Historically, children-provided an economic contribution to their families, especially in the agriculture areas. Other values include the psychological benefit derived by parents or as gifts from Gods. Parents who think of children as economic contributor to continue the productivity of the family business may socialize their children to work hard and may minimize emotions that can distract a child from their work. However, if parents believe that children are gifts from God, they may encourage positive emotion socialization as a means of gratitude for the existence of that child.

The fourth frame is the ways children learn. Halberstadt and Lozada (2011) outlined that this frame concerns belief about children learning that related to emotion socialization and children's' outcomes: "when," "whether," "who," and "how". Regarding the "when" of learning, parents' perception of the age which young children as seen as capable to learn various tasks varies across cultures. Parents who believe that young children are emotionally capable may provide the environment and scaffolding that allows them to meet parental goals, compared to parents who do not believe that young children are emotionally capable. The second kind of belief is whether children acquire competencies via maturation or teaching. Parents who believe that development is maturational will do different emotion socialization practices than parents who believe learning is a process that requires teaching. The third kind of beliefs is "who is in charge?". In some cultures, parents have important roles as teachers and guides for their children, yet other cultures assume that when children are ready to learn, they will look to other children as their guides to learn about appropriate emotion-related behaviors. The next kind of belief concerns how children learns. This belief includes using discipline to instruct, telling children what to do and expecting that they will do it then, providing children with opportunities to be active participants in their learning process, scaffolding children's next steps, or co-creating knowledge through discussion.

The fifth frame is cultural value of emotional experience and expression. Halberstadt and Lozada (2011) stated that there was variability in the values and frequency of emotional expression and experience within cultures of collectivism and individualism. Some cultures may value or devalue emotional experience in general, value certain emotions more than other emotions, value certain levels of emotional arousal more than other levels, or value social emotions contexts. For example, in Nepal, there are differences in socialization of emotions between people Tamang and Brahman ethnic (Cole, Tamang, Shrestha, 2006), where the Tamang do not support the emotion of anger in children but give an explanation when children feel embarrassed, consistent with their view that the competent children are socially graceful and never angry. While Brahman respond to the emotion of anger by giving an explanation but ignore the emotions of shame, consistent with the privileges and 
duties of the high caste status. Similarly, in Indonesian culture there is variation within the culture of collectivism in Javanese and Batak ethnic. Batak people are more expressive and more open in expressing emotion, while the Javanese are more cautious in expressing feelings and "hiding" their original feelings as the manifestation of the principles of isin or embarrassed and sungkan or shy (Suseno, 2001). Expressing spontaneous feelings is considered less polite, so emotions will be hidden or should not be shown openly. Javanese people always try to put everything in balance, or inclined in the middle ( $s a k$ ing madya), including in expressing emotions (Kurniawan \& Hasanat, 2007).

Those emotional expression and emotion socialization variations among cultures cannot be separated from specific cultural values that applied in a community. For example, behind the Javanese cautious way in expressing negative feelings, there are some specific culture values that guide individual in controlling their emotion to keep social harmony. Some central culture elements in Javanese culture context are rila, nrima, and sabar (Endraswara, 2012). Rila is a willingness to give all belonging to, the ability, and the work of one of to the Lord. Nrima means not exert oneself, is satisfied with the fate of and obligations, not being rebellious. Sabar means being patient, the absence of anger or emotional burst. There are also several Javanese philosophies as some guides to regulate the emotion. Endraswara (2012) stated some of them, such as ngono ya ngono ning aja ngono (means individual should conform with others). Sing bisa angon mangsa (means individual should be able to talk and behave wisely). Seje kulit seje anggit, seje uwong seje omong (everyone differs in saying and thinking) teaches individual to appreciate and understand other person wisely so they can keep a harmonius relationship or karyenak tyasing. Bungah ing pengalem, aja susah ing panacad, aja mongkog ing pambombong, aja kendho ing panyendhu (do not feel too proud when being praised, do not too sad when being criticized) and wong seneng ora kurang pengalem, wong sengit ora kurang panacad stresses the importance of emotional balance emotion in social relationship. The big picture about emotion socialization can be understood better if we also consider the role of specific culture values or principles.

\section{IMPLICATIONS}

Based on the description above, it can be understood that the cultural values colored the process of parental emotion socialization, and that socialization plays an important role for developing children's' emotional competence. As the consequence, the design of interventions to optimize the development of children's emotional competence need to be more sensitive, not only to universal cultural values, but also culture-specific values that relevant to the subject. The next implication is in terms of research design. The five cultural frames showed that the Western culture-based assumptions which emphasizes the expression of emotions openly as an important aspect to the development of emotional competence in children may be less appropriate to be applied without modification to the cultures in which the expression of emotions is done carefully to maintain social harmony. In other words, further research needs to prepare research designs, including the culturally-sensitive assessment instruments. In addition, related to the cultural role of the socialization of emotions, a study conducted in a laboratory setting can cause discomfort for participants from less emotionally expressive cultural background. Therefore, the natural setting of research needs to be considered.

\section{CONCLUSIONS}

One of antecedent important factors to the emotional competence in children is parental emotion socialization. The emotion socialization takes place through three possible mechanisms, namely modeling, contingency, and coaching. In the emotion socialization process, cultural aspects also play an important role, where variations in emotion parental socialization practices and goals reflect different cultural values. Parents' pre-existing beliefs and values regarding emotion may lead to various degrees of responses to their children's' emotional expressions, and provide important guides to children's' experience, expression, and understanding of emotion. In other words, children's emotion competence is shaped not only by their temperament, but also contextually, particularly through interaction with their parents as recipients and conveyors of the values and goals of their culture. The five cultural frames can explain the parental emotion socialization from a more culturally-sensitive perspective, include collectivism or individualism, power distance, children's place in family and culture, ways children learn, and value of emotional experience and expression.

Some recommendations for next research themes are to explore the role of (both universal and culturespecific) cultural values to parental emotion socialization, to design a model of the development of emotional competence based on cultural values, and to develop culturally-based parenting programs or interventions to optimize the emotional competence development of Indonesian children. 


\section{REFERENCES}

Abraham, R. (2004). Emotional competence as antecedent to performance: A contingency framework. Genetic, Social, and General Psychology Monographs, 130 (2), 117-143.

Ashiabi, G.S. (2000). Promoting the emotional development of preschoolers. Early Childhood Education Journal, 28 (2), 79-84.

Brackett, M.A., Mayer, J.D., \& Warner, R.M. (2004). Emotional intelligence and its relation to everyday behavior. Personality and Individual Differences, 36, p.1387-1402.

Brackett, M.A., \& Katulak, N.A. (2006). Emotional intelligence in the classroom: Skill-based training for teachers dan students. In J. Ciarrochi \& J.D. Mayer (Eds.). Improving emotional intelligence: A practitioners guide. New York: Psychology Press/Taylor \& Francis.

Brasseur, S., Grégoire, J., Bourdu, R, \& Mikolajczak, M. (2013). The profile of emotional competence (PEC): Development and validation of a self-reported measure that fits dimensions of emotional competence theory. PLoS ONE 8 (5), e62635.

Doi:1371/journal.pone.0062635.

Cole, P.M., Tamang, B.L., \& Shresta, S. (2006). Cultural variations in the socialization of young children's anger and shame. Child Development, 77 (5), 1237-1251.

Cole, P.M., Dennis, T.A., Smith-Simon, K.E., \& Cohen, L.H. (2009). Preschoolers' emotion regulation strategy understanding: Relations with emotion socialization and child selfregulation. Social Development, 18 (2), 324-352.

Denham, S. A., Mason, T., Kochanoff, A., Neal, K., \& Hamada, H. (2003). Emotional development. In Dawn Cavalieri, (Ed.), International Encyclopedia of Marriage and Family Relationships, Second Edition. New York: Macmillan.

Denham, S.A., Mitchell-Coppeland, J., Stranberg, K., Auerbach, S., \& Blair, K. (1997). Parental contributions to preschoolers' emotional competence: Direct and indirect effects. Motivation and Emotion, 21 (1), 65-86.

Edwards, A., Shipman, K., \& Brown, A. (2005). The socialization of emotional understanding: A comparison of neglectful and non-neglectful mothers and their children. Child Maltreatment, 10 (3), 293-304.

Eisenberg, N., Pidada, S., \& Liew, J. (2001). The relations of regulation and negative emotionality to Indonesian children's social functioning. Child Development, 72 (6). 1747-1763.

Endraswara, S. (2012). Falsafah Hidup Orang Jawa. Yogyakarta: Penerbit Cakrawala.

Farina, E., \& Belacchi, C. (2014). The relationship between emotional competence and hostile/prosocial behavior in Albanian preschoolers: An exploratory study. School Psychology International, 35 (5), 475-484. Doi: 10.1177/0143034313511011.

Fernandez-Berrocal, P., \& Ruiz, D. (2008). Emotional intelligence in education. Electronic Journal of Research in Educational Psychology, vol.6 (2), 421-436.

Garner, P.W., \& Waajid, B. (2008). The associations of emotion knowledge and teacher-child relationships to preschool children's schoolrelated developmental competence. Journal of Applied Developmental Psychology, 29, 89-100. Doi: 10.1016/j.appdev.2007.12.001.

Graziano, P.A., et al. (2007). The role of emotion regulation in children's early academic success. Journal of School Psychology, 45, 3-19.

Halberstadt, A.G., \& Lozada, F.T. (2011). Emotion development in infancy through the lens of culture. Emotion Review, 3 (2), 158-168.

Havighurst, S.S. Harley, A., \& Prior, M. (2004). Building preschool children emotional competence: A parenting program. Early Education \& Development, 15 (4), 423-447.

Havighurst, S.S., Wilson, K,R., Harley, A.E., Prior, M.R., \& Kehoe, C. (2010). Tuning in to kids: Improving emotion socialization practices in parents of preschool children, findings from a community trial. Jornal of Child Psychology and Psychiatry, 51 (12), 1342-1350. Doi: 10.1111/j.1469-7610.2010.02303.x.

Jones, S., Eisenberg, N., Fabes, R.A., \& MacKinnon, D.P. (2002). Parents' reactions to elementary school children's negative emotions: Relations to social and emotional functioning at school. Merrill-Palmer Quarterly, 48 (2), 133-159.

Kurniawan, A.P., \& Hasanat, N.U. (2007). Perbedaan ekspresi emosi pada beberapa tingkat generasi suku Jawa di Yogyakarta. Jurnal Psikologi, 34 (1), 1-17.

Lopez, S.R., Garcia, J.I.R., Ullman, J.B., Kopelowicz, A., Jenkins, K., Breitborde, N.J.K,m \& Placencia, P. (2009). Cultural variability in the manifestation of expressed emotion. Family Process, 48 (2), 179-194.

Lunkenheimer, E.S., Shields, A.M., \& Cortina, K.S. (2007). Parental emotion coaching and dismissing in family interaction. Social Development, 16 (2), 232-248. 
Magdalena, S.M. (2013). Social and emotional competence, predictors of school adjustment. Procedia Social and Behavioral Sciences, 76, 29-33.

Markus, H. R., \& Kitayama, S. (1994). A collective fear of the collective: Implications for selves and theories of selves. Personality and Social Psychology Bulletin, 20, 568-579.

Mesquita, B., \& Karasawa, M. (2004). Selfconscious emotions as dynamic cultural processes. Psychological Inquiry, 15, 161-166.

Nelson, J., O’Brien, M., Calkins, S.D., Leerkes, E.M., \& Marcovitch, S. (2012). Maternal expressive style and children's emotional development. Infant \& Child Development, 21 (3), 267-286.

Perlman, S.B., Camras, L.A., \& Pelphrey, K.A. (2008). Physiology and functioning: Parents' vagal tone, emotion socialization, and children's emotion knowledge. Journal of Experimental Child Psychology, 100, 308-315.

Suseno, F. M. (2001). Etika Jawa: Sebuah Analisa Falsafi tentang Kebijaksanaan Hidup Jawa. Jakarta: Gramedia Pustaka Utama.

Tao, A., Zhou, Q., Wang, Y. (2010). Parental reactions to children's negative emotions:
Prospective relations to Chinese children's psychological adjustment. Journal of Family Psychology, 24 (2), 135-144.

Trentacosta, C.J., \& Shaw, D.S. 2009. Emotional selfregulation, peer rejection, and antisocial behavior: Developmental associations from aerly childhood to early adolescence. Journal of Applied Developmental Psychology, 30, 356365.

Wang, Q. (2001). “Did you have fun?”: American and Chinese mother-child conversations about shared emotional experiences. Cognitive Development, 16, 693-715.

Wang, Q., \& Fivush, R. (2005). Mother-child conversations of emotionally salient events: Exploring the functions of emotional reminiscing in European-American and Chinese families. Social Development, 14(3), 473-495.

Warren, H.K., \& Stifter, C.A. (2007). Maternal emotion-related socialization and preschoolers' developing emotion self-awareness. Social Development, 17 (2), 239-258. Doi: 10.1111/j.1467-9507.2007.00423. 